HORTSCIENCE 25(8):916-918. 1990.

\title{
Transplanting Bearing Pecan Trees
}

\author{
Bruce W. Wood ${ }^{1}$, Jerry A. Payne ${ }^{2}$, and Owen Jones ${ }^{3}$ \\ Southeastern Fruit and Tree Nut Research Laboratory, Agricultural \\ Research Service, U.S. Department of Agriculture, P.O. Box 87, Byron, \\ GA 31008 \\ Additional index words. Carya illinoensis, orchard establishment, pruning
}

\begin{abstract}
Overcrowding in young high-density pecan [ Carya illinoensis (Wangenh.) C. Koch] orchards has prompted a study of tree transplanting and evaluation of survival and tree performance. Shoot growth and nut production characteristics of 13year-old 'Stuart' and 'Farley' pecan trees subjected to different stubbing and pruning treatments and then transplanted with a large tree spade indicated that transplants can survive with little or no pruning if moved when dormant. Shoot regrowth was proportional to the degree of pruning, and nut production was inversely proportional to the degree of pruning.
\end{abstract}

Pecan orchards are long-term investments, with trees being productive in excess of 300 years. This relatively long life span, coupled with the rapid early growth of young trees, results in commercial orchards becoming crowded after 10 to 1.5 years. This overcrowding has traditionally been relieved by tree removal as necessary (Cracker, 1986). Alternatives, such as pruning, often are more expensive and generally impractical and only delay the eventual removal of trees (Sparks, 1981). The availability of equipment capable of relocating large trees, such as tree spades (Ford and Foote, 1973), provides an alternative. While semi-mature pecan trees are considered to be difficult to successfully transplant (Himelick, 1981), preliminary studies using tree spades to transplant small trees have provided evidence that the concept might be practical for pecan (Herrera, 1987; Laiche, 1986; Madden et al., 1980). Tree spades can be used to move small- to medium-size trees long distances and more quickly than with any other transplant method.

The U.S. pecan industry is currently characterized by a substantial acreage of high-

Received for publication 20 Oct. 1989. Mention of a trade name(s) does not constitute a guarantee or endorsement by the USDA over other products. The cost of publishing this paper was defrayed in part by the payment of page charges. Under postal regulations, this paper therefore must be hereby marked advertisement solely to indicate this fact ${ }^{1}$ Horticulturist.

${ }^{2}$ Entomologist.

${ }^{3}$ President, Native Tree, 1410 Johnson Ferry Rd. Marietta, GA 30062. density commercial orchards that soon will become excessively crowded. This report, therefore, provides orchard managers information on the feasibility of transplanting semimature trees.

Pruning and season (Expt. 1 ). The feasibility of transplanting semi-mature pecan trees using a tree spade was evaluated in association with various stubbing treatments and the season of transplanting. The experiment used 13-year-old 'Stuart' trees managed under commercial-like conditions (Cracker, 1986). Trees were growing at about a $9 \mathrm{x}$ 9-m. spacing, with trunk diameters ranging from $\approx 12$ to $20 \mathrm{~cm}$. The experiment consisted of three stubbing treatments plus that of a control. Stubbing treatments resulted with reductions in the length of scaffold limbs by stubbing back by 50\%, 75\%, and 100\% (Fig. 1A); the last involved the removal of all secondary branches; hence, no shoots or branches remained on the trees. Trees were stubbed and immediately transplanted in mid-Mar. or early Aug. 1982. Trees were planted in a completely randomized design with three to eight replicates per treatment (one tree per experimental unit). Major stubbing cuts were coated with asphalt immediately after transplanting. Transplanting was by a truckmounted Big John (Model 88) tree spade (Big John, Herber Springs, Ark.), giving a conical root plug $224 \mathrm{~cm}$ in diameter and 152 $\mathrm{cm}$ in height and producing a root ball consisting of $\approx 4100 \mathrm{~kg}$ of soil. Transplanted trees were established at an orchard spacing of $18 \times 18 \mathrm{~m}$. A berm was constructed just beyond the root ball with trees receiving $\approx 385$ 

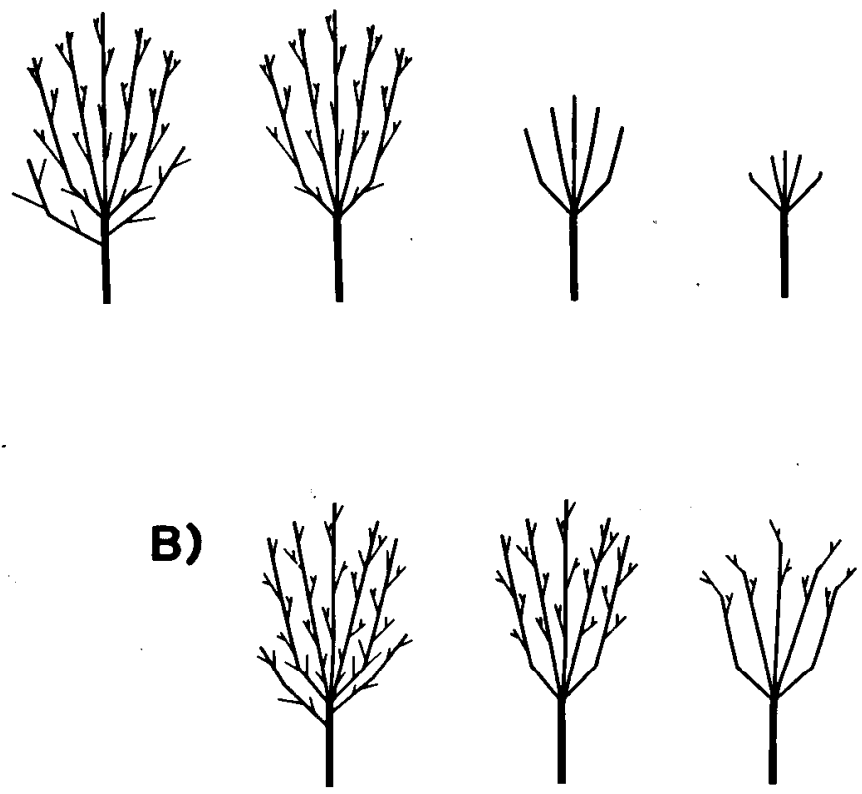

Fig. 1. Schematic of stubbing (A) treatments imposed on 13-year-old 'Stuart' pecan trees before transplanting (Expt. 1). (left to right) Pretransplanted condition, control, and scaffold limb stubbing at $50 \%, 75 \%$, and $100 \%$, respectively. Pruning levels (B) on 14-year-old 'Farley' pecan trees (Expt. 2). (left to right) Pretransplanted condition, control, and pruned.
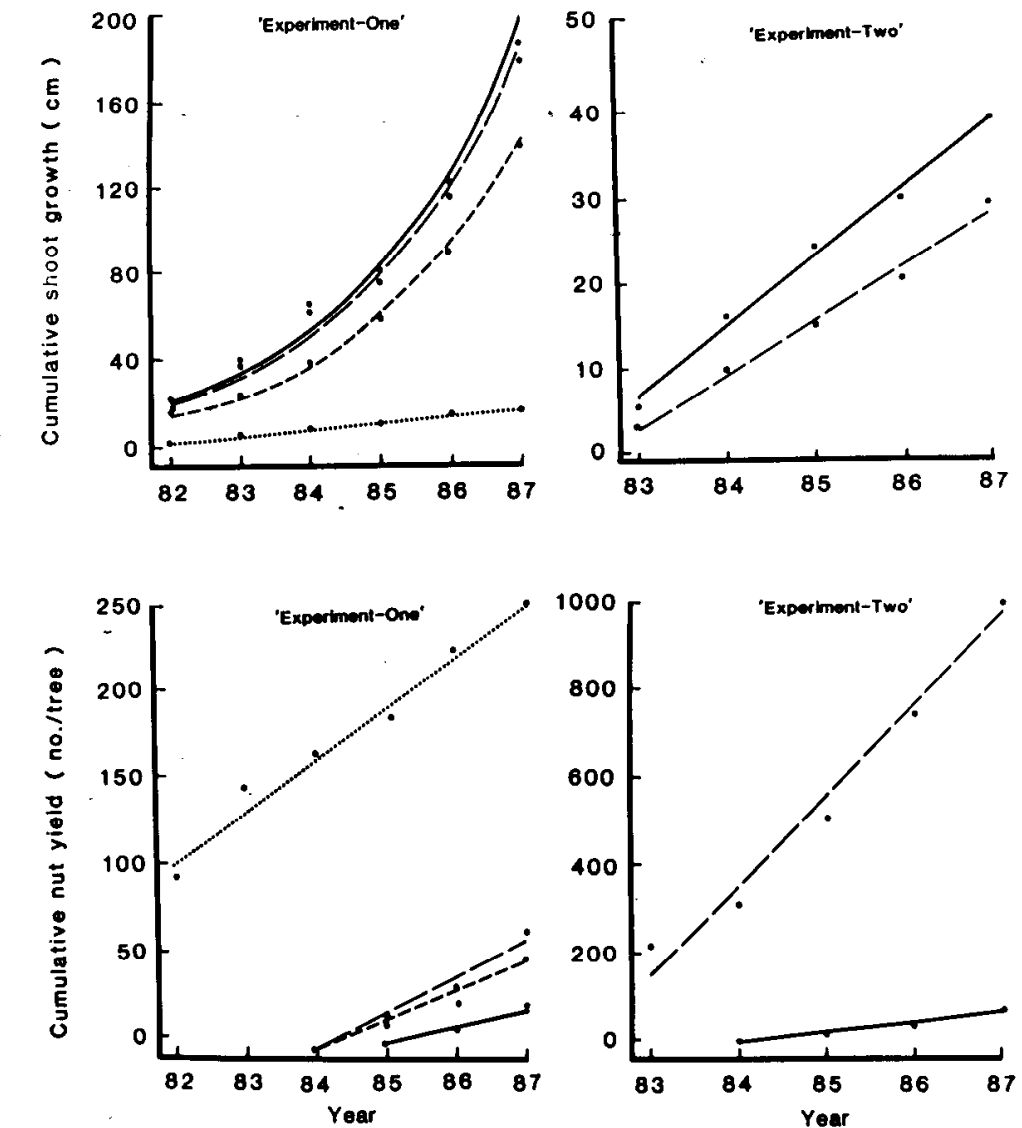

Fig. 2. Cumulative shoot growth and yield reponse of pecan trees after transplanting. Expt. 1, 13year-old 'Stuart' pecan trees: best-fit regressions for cumulative shoot growth for indicated percentages of stubbing of scaffold limbs: $0 \%(\cdots \cdots) \mathrm{y}=-216+3 \mathrm{x}\left(r^{2}=0.99\right) ; 50 \%(---) \mathrm{y}=4.5$ $\times 10^{-13} \mathrm{e}^{0.41 \times}\left(r^{2}=0.96\right) ; 75 \%(---) \mathrm{y}=1.5 \times 10^{-14} \mathrm{e}^{0.43 \times}\left(r^{2}=0.98\right) ; 100 \%(\longrightarrow) \mathrm{y}=$ $3.1 \times 10^{-15} \mathrm{e}^{0.44 x}\left(r^{2}=0.96\right)$. Best-fit regressions for cumulative nut yield for the above treatments are $\mathrm{y}=-2237+29 \mathrm{x}\left(r^{2}=0.99\right) ; \mathrm{y}=-1358+16 \mathrm{x}\left(r^{2}=0.99\right) ; \mathrm{y}=-1.770+21 \mathrm{x}\left(r^{2}=\right.$ $0.96)$; and $\mathrm{y}=-808+9 \mathrm{x}\left(r^{2}=0.98\right)$, respectively. Expt. 2, 14-year-old 'Farley' trees: best-fit regressions for pruned $(\longrightarrow)$ and control $(--)$ trees are $\mathrm{y}=652+8 \mathrm{x}\left(r^{2}=0.99\right)$ and $\mathrm{y}=$ $498+6 \mathrm{x}\left(r^{2}=0.99\right)$ for shoot growth and $\mathrm{y}=1644+19 \mathrm{x}\left(r^{2}=0.94\right)$ and $\mathrm{y}=-16,907+$ $206 \mathrm{x}\left(r^{2}=0.98\right)$ for cumulative nut yield of pruned and control treatments, respectively. Regressions are significant at $P \leq 0.05$. liter of water per tree biweekly during the first growing season and no irrigation in subsequent years. Trees were fertilized, within the transplant zone, with $1000 \mathrm{~g}$ of $10 \mathrm{~N}$ $10 \mathrm{P}-10 \mathrm{~K}$ in March of the second growing season and, thereafter, in accordance with Georgia Extension Service recommendations for commercial orchards (Cracker, 1986). Transplanted trees were pruned in Mar. 1983, leaving a single shoot at the stubs of the scaffold limbs to encourage new scaffold development by removing competing shoots. Trees were then monitored for mortality, shoot growth, and yield from 1982 to 1987.

Retention of tree structure (Expt. 2). This study assessed the feasibility of tree-spade transplanting of pecan trees while retaining the general structure of the tree. The experiment used 14-year-old 'Farley' trees that had been under commercial-like-management for several years previously. Average tree diameter was $19 \mathrm{~cm}$. The experiment consisted of a control and a single pruning treatment. The control tree had the lower one-third of the limbs removed before transplanting, since previous experience had shown that lower limbs generally interfered with the functioning of the tree spade equipment. The second treatment was the same as that received by the control plus the additional removal of secondary limbs from the lower half of each remaining scaffold limb plus a drop-crotch cut (the removal of the primary branch, while leaving the secondary branch, at a fork in the limb) to reduce scaffold lengths ( and crown size) by $\approx 25 \%$. These two treatments removed $\approx 40 \%$ and $80 \%$, respectively, of the potential leaf surface of the tree. Since 'Farley' typically forms a crotch with three to six major scaffolds, and no central leader, transplanted trees retained several scaffolds. Pruning and transplanting were done in late Mar. 1983. Natural budbreak at the research plots normally occurs on 1 Apr. Transplanting was with a Big John (Model-78) transplanter, giving a $3400-\mathrm{kg}$ conical soil plug with a $198-\mathrm{cm}$ diameter and a $137-\mathrm{cm}$ depth. Trees were reestablished on a $18 \times 18-\mathrm{m}$ spacing and supplementally irrigated with 200 liters of water per week by drip emitters within the transplant soil-plug zone. Fertilization was described in Expt. 1.

Experiment 1. Pecan trees, typical of those in young, crowded high-density orchards, can be successfully transplanted without a high degree of mortality. Survival was related to the degree of stubbing and season of planting (Table 1). The March transplanting produced very low mortality (58\%), but that in August resulted in very high mortality (nearly $100 \%$ ). There was no detectable effect of degree of stubbing on survival of Marchplanted trees; however, the greater the degree of stubbing, the better survival of August-planted trees. These data support the general principle that, if at all possible, transplanting should be done in the spring rather than in the summer (or when most dormant). While it is not surprising that August-transplanted trees would survive poorly, this treatment was included to provide an estimate of how late in the season trees could 
Table 1. Influence of stubbing of scaffold branches and pruning on survival of transplanted 13-yearold 'Stuart' (Expt. 1) and 14-year-old 'Farley' (Expt. 2) pecan trees.

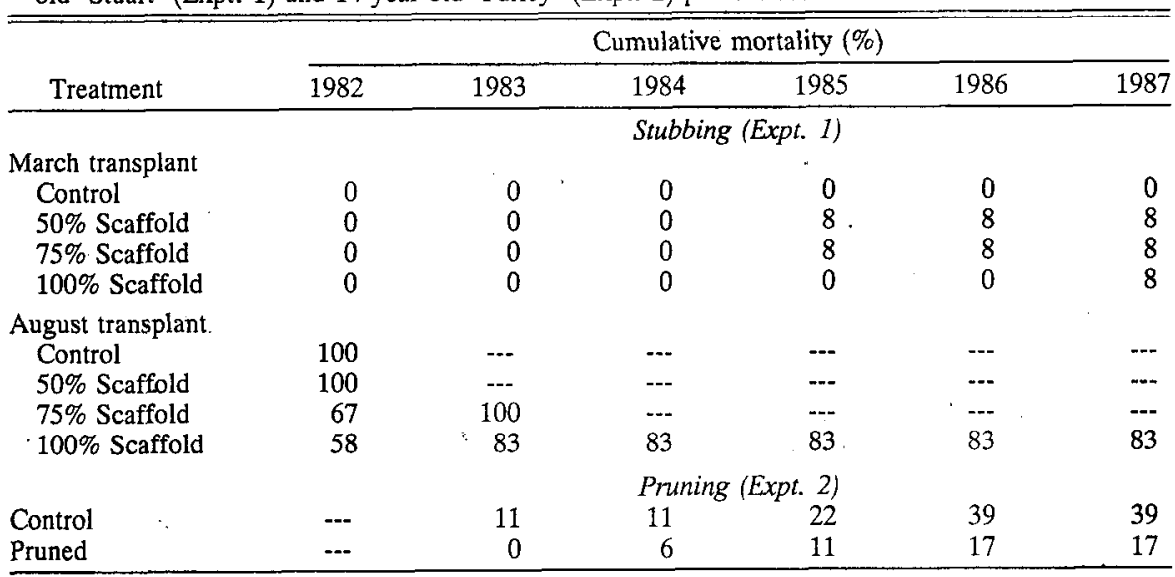

be successfully transplanted and how pecan responds to transplanting stresses. The poor survival of August-transplanted trees appears to have been due to excessive shoot regrowth (50 to 100 vegetative shoots $\approx 40$ to $60 \mathrm{~cm}$ long per tree)' after pruning (mid-March) and before transplanting (mid-August); thus, the drastically reduced root system was unable to supply adequate water, even though trees were kept well-watered.

Shoot regrowth was minimal in the control, but increased. proportionally with the severity of stubbing (Fig. 2). Growth of terminal shoots in the control was essentially constant during the subsequent 5 years after transplanting; however, regrowth from the various stubbing treatments was curvilinear, exceeding previous-season growth in subsequent years. Shoot and foliage regrowth from the three stubbing treatments were vigorous and healthy, whereas growth by the control was very weak. This result indicates that stubbing or heavy pruning is necessary if acceptable shoot regrowth is to be obtained. The disadvantage of stubbing was that is suppressed nut production for 3 to 4 years after transplanting, whereas control trees continued to produce an annual (but minute) nut crop (Fig. 2). Even by 6 years after transplanting, stubbed trees were commercially unproductive,

Experiment 2. In this experiment, which was designed to test the survival and growth of trees pruned to retain their original scaffold limb stature, the control required $\approx 5$ min to prune, whereas the treatment required $\approx 30 \mathrm{~min} /$ tree. The removal of an additional $40 \%$ of total potential leaf area over that of the control resulted in slightly stronger shoot growth of existing shoots, but considerably less nut yield (Fig. 2). The severe pruning resulted in an induction of numerous new shoots along the length of the original scaffold limbs. This new growth obviously detracted from the growth of original shoots and caused these trees to become more vegetative than the controls.

Both the control and the pruned trees responded with poor shoot growth and low nut production during the 5-year study. Cumulative growth during this period was linear for both treatments, indicating that even after 5 years, tree vigor had not improved over that of the earliest year of the study. This relationship suggests that, despite fertilization and supplemental irrigation, there was more shoot growth or foliage than the root system could easily supply. The level of demand on water and assimilates by shoot tissues appears to be high enough to cause the tree to barely sustain growth. Therefore, severe crown pruning seems to be necessary if the trees are to rapidly regain vigor and productivity. We estimate that the transplanting technique used in this study reduced the trees' root biomass by $\approx 90 \%$; therefore, it appears that the leaf area (and thus respiratory area) of the crown should be reduced proportionally. Also, in this study, trees were of similar diameters; hence, there was no observable differential response due to tree size; however, one would expect tree vigor to be higher for trees of smaller diameter.

Tree-spade transplanting of semi-mature (10 to $20 \mathrm{~cm}$ in diameter) pecan trees in this study was successful when trees were severely stubbed and transplanted in the dormant season. While stubbing enhanced survival, it forced the tree into a vegetative growth phase, delaying nut production. Seating major wounds that are slow to heal and sirable of the four treatments because cut surfaces at the stubbing points are smaller in diameter and quicker to heal over. By the 6th year after transplanting, this treatment had produced vigorous trees with a canopy height of $\approx 80 \%$ of the unpruned control. During the first post-transplant growing season, all three stubbing treatments produced copious vegetative shoots that required thinning before a desirable limb structure could be established; however, no limb pruning or training was deemed necessary in subsequent years.

The $100 \%$ stubbing treatment produced a vere stubbing has the disadvantage of cremay weaken limb structure. Therefore, the $50 \%$ stubbing treatment may be the most de- fence post-like transplant that survived well but resulted in a weak tree because severe stubbing produced a large wound that failed to heal before decay organisms had destroyed a substantial portion of the remaining trunk. Similarly, stubbed trees transplanted in the arid western United States reportedly were unaffected by decay and appear to have healed without a significant loss of structural strength (O.J., personal observation). Extreme stubbing would appear to be more successful in an arid climate.

These studies indicate that trees should be pruned such that the percentage of crown volume retained would be no more than the percentage of root volume left after transplanting. A practical method would appear to be that of stubbing scaffold limbs at $\approx 50 \%$ of their length. The recovery of trees in this study would likely have bee-n faster if they had received irrigation beyond the first growing season. It also appeared that the smaller-diameter trees were recovering faster than larger trees. Additional factors that would likely enhance recovery are the disruption of the glazed soil surface produced by the cutting spades and addition of a liquid organic fertilizer into the hole before transplanting. The weak regrowth, slow return to nut productivity, and probable increased susceptibility of trees to biotic and abiotic stresses observed in this study indicate that tree-spade transplantation may not be an economically viable commercial practice for overcoming the problem of orchard overcrowding. This becomes increasingly evident when one considers the direct costs of transplanting [between $\$ 50$ and $\$ 75$ per tree (O.J., personal communication)] and the fact that nursery trees (costing between $\$ 6-\$ 10$ ) typically come into economic production within 5 to 8 years after establishment (Wood et al., 1980).

\section{Literature Cited}

Cracker, T.F. 1986. Commercial pecan production in Georgia. Univ. of Georgia Coop. Ext. Serv. Bul. 609.

Ford, D.H. and L.E. Foote. 1973. Large tree moving. Weeds, Trees \&Turf June:10-11, 20$21,44-45,54$.

Herrera, E. 1987. New Mexico grower meets with success in tree transplanting. Pecan South 21(3):27-29.

Himelick, E.B. 1981. Transplanting manual for trees and shrubs. Revision II. Intl. Soc. Aboriculture, Urbana, Ill.

Laiche, A.J., Jr. 1986. Effects of tree spade size and tree size on the initial growth of transplanted pecan trees. Proc. Southeastern Pecan Growers Assn. 79:67-71.

Madden, G., H. Tisdale, and B. Price. 1980. Results of transplanting large pecan trees and grafting success in same season moved. Pecan South 7(1):8-10.

Sparks, D. 1981. Physiology-Site, growth, flowering, fruiting and nutrition, p. 211-239. In: R.A. Jaynes (ed.). Nut tree culture in North America. Northern Nut Growers Assn.

Wood, B.W., R.E. Hunter, and J.L. McMeans. 1980. Evaluation of pecan cultivars and promising selections in southwest Georgia. Proc. Southeastern Pecan Growers Assn. 73:19-83. 